\title{
Performance Comparison of Commercial Enzymes for The Synthesis of Glucosamine by Chitosan Hydrolysis in The Presence of Surfactant
}

\author{
Nur Rokhati ${ }^{1}$, Heru Susanto ${ }^{1}$, Titik Istirokhatun $^{2}$, Purwono ${ }^{2}$ and Bambang Pramudono ${ }^{1, *}$ \\ ${ }^{1}$ Department of Chemical Engineering, Faculty of Engineering, Diponegoro University \\ ${ }^{2}$ Department of Environmental Engineering, Faculty of Engineering, Diponegoro University
}

\begin{abstract}
Glucosamine has attracted much attention due to its potential biological, pharmaceutical and nutritional effects. In this research, glucosamine was prepared by enzymatic hydrolysis of low molecule weight chitosan with nonionic surfactant (Tween 80 ) addition. The change in reducing sugar content was used as an indicator for the hydrolysis reaction rate. The results showed that addition of Tween $80(1 \%, w / w)$ increases the formation of reducing sugars approximately two times higher than without Tween 80 addition. Hydrolysis using a combination of cellulase and $\beta$-glucosidase showed higher reaction rate than using a combination of cellobiohydrolase and $\beta$-glucosidase or using $\beta$-glucosidase only. The combination of cellulase and $\beta$-glucosidase showed optimum hydrolysis at reaction time of 24 hours. High-performance liquid chromatography (HPLC) analysis of the glucosamine product showed typical peak distributions the same as those of commercial standard glucosamine hydrochloride.
\end{abstract}

\section{Introduction}

Glucosamine, 2-amino-2-deoxy-D-glucose, is a common monosaccharide that is derived from chitosan [1] and the biochemical precursor of all amino sugars in the human body [2]. Glucosamine is receiving much more attention recently because of its has therapeutic potential and is used to prevent or treat a wide variety of diseases. Many biological, pharmaceutical and nutrimental effects of glucosamine have been reported, such as liver protective effect [3], treatment of osteoporosis [1], cancer [4], skin wound healing [5], healing of surgical incisions [5], inflammation [6], bone regeneration [7], and so on.

Glucosamine can be produced by either chemical or enzymatic hydrolysis of chitosan. In the case of commercial production, glucosamine was prepared by complete hydrolysis of chitosan using concentrated $\mathrm{HCl}$. Chemical hydrolysis has some disadvantages, such as low yield, acidic waste by the use of concentrated hydrochloric acid, chemical modifications of glucose ring and so on [1]. Therefore, enhancing of Glucosamine production by enzymatic hydrolysis gets a lot of attention.

Chitosanases are a group of specific complex hydrolytic enzymes that catalyze depolymerization of chitosan. Chitosanase hydrolyzes chitosan to oligoglucosamine chains. Subsequently $\beta$-Dglucosaminidase hydrolyzes oligomers to glucosamine

\footnotetext{
Corresponding author: pramudono@live.undip.ac.id
}

monomers. However, Chitosanases are very expensive and unavailable in bulk quantities for commercial application. Xia et al., [8] reported that some nonspecific enzymes such as cellulases, lipases, and proteases have the ability to hydrolyze chitosan and those were comparable with the results achieved by chitosanase. However, these enzymes were added at relatively high concentrations.

In this paper, we report the preparation of glucosamine product by hydrolyzing chitosan using cellulase and glucosidase with surfactant Tween 80 addition. The addition of surfactant was expected to be able to decrease the amount of enzyme used. The optimal reaction conditions and the characterization of the glucosamine product were investigated.

\section{Materials And Methods}

\subsection{Materials}

Raw chitosan is low molecule weight chitosan was purchased from Sigma-Aldrich. The cellulase enzyme (Cat. 22178), Cellobiohydrolase enzyme (Cat. E6412100UN), and $\beta$-Glucosidase enzyme (Cat. 49290-1G) were purchased from Sigma-Aldrich. Acetic acid glacial $\left(\mathrm{CH}_{3} \mathrm{COOH}\right)$, sodium carbonate $\left(\mathrm{Na}_{2} \mathrm{CO}_{3}\right)$, and 
surfactant Tween 80 were purchased from Merck Germany. Potassium ferricyanide $\left(\mathrm{K}_{3}\left(\mathrm{Fe}(\mathrm{CN})_{6}\right)\right)$ was purchased from Sigma-Aldrich, Germany.

\subsection{Hydrolysis of Chitosan}

The method of chitosan hydrolysis followed our previous publication [9]. Briefly, chitosan was dissolved in acetic acid/sodium acetate buffer $(0.1 \mathrm{M})$ at a concentration of $1 \%(\mathrm{w} / \mathrm{v})$ and was mixed with the surfactant (Tween $80,1 \% \mathrm{w} / \mathrm{w}$ of chitosan). Chitosan solution $(50 \mathrm{~mL})$ was treated using an enzyme with the ratio $1: 100(\mathrm{w} / \mathrm{w})$. The reaction mixture was incubated at $50^{\circ} \mathrm{C}$ with constant stirring $(100 \mathrm{rpm})$. After hydrolysis, the enzyme was inactivated at water bath $100{ }^{\circ} \mathrm{C}$ for 10 $\min$. Then the amount of reducing sugar of the filtrate was measured.

\subsection{Crystallization of Glucosamine Product}

The filtrate from the hydrolysis was filtered using an ultrafiltration membrane and added with $0.02 \mathrm{~N} \mathrm{HCl}$ solutions. Then it was concentrated by evaporation at low pressure until the final volume was $10 \%$ of the initial solution. The concentrate was mixed with an equal volume of ethanol yielding a precipitate. The precipitate was collected by centrifugation, washed with ethanol several times, and dried in a vacuum oven.

\subsection{Analysis}

Analysis of total reducing sugars was conducted using Imoto method [10]. The absorbance of the mixture solution was measured at $420 \mathrm{~nm}$. Total reducing sugars was calculated based on a standard curve obtained with D-glucosamine $\mathrm{HCl}$.

The glucosamine product was analyzed by using HPLC on Chromolith ${ }^{\circledR}$ Performance $\mathrm{NH}_{2}$ column $(100 \mathrm{x}$ $4,6 \mathrm{~mm})$ at temperature of $30^{\circ} \mathrm{C}$. The Mobile Phase is Acetonitrile: Distilled Water $(60: 40 \mathrm{v} / \mathrm{v})$ with a flow rate was $0.8 \mathrm{ml} / \mathrm{min}$. The detector used was refractive index detector (RID) with injection volume $20 \mu \mathrm{l}$ at running time $30 \mathrm{~min}$.

FTIR spectra were recorded with $\mathrm{KBr}$ powder using the instrument IR Prestige-21 Shimadzu, Japan. Thirtytwo scans were performed at a resolution of $4 \mathrm{~cm}^{-1}$ and a temperature of $21 \pm 1^{\circ} \mathrm{C}$ over the wavelength range of 500 $-4000 \mathrm{~cm}^{-1}$.

\section{Results And Discussion}

\subsection{Effect of Enzyme Type}

Cellulase is an endo-acting hydrolase, which performs random cuts at internal amorphous sites of the polysaccharide chain generating oligosaccharides of various lengths responsible for decreasing degree of polymerization of substrates [11]. Whereas cellobiohydrolase and $\beta$-glucosidases are exo-acting hydrolase. Cellobiohydrolase acts in a processive manner from the ends of polysaccharide chains, processing along the polymer chain while liberating disaccharide as the major product. $\beta$-Glucosidases attack the substrates from the nonreducing-end, producing monosaccharide [12]. In this study, the effect of enzyme type, i.e., $\beta$-glucosidase only, the combination of cellulase - $\beta$-glucosidase, and the combination of cellobiohydrolase - $\beta$-glucosidase, on chitosan hydrolysis was investigated. The nonionic surfactant (Tween 80) was added in chitosan solution.

The formation of reducing sugar indicates the activity of an enzyme that cleaves glycosidic bond in chitosan polymer [13]. Therefore, the activities of chitosan enzymatic hydrolyzed can also study by measuring reducing sugar content. The reducing sugar formation from hydrolysis chitosan with various enzyme types at reaction time 24 hours showed in Fig. 1. The hydrolysis using a combination of cellulase - $\beta$-glucosidase showed higher reaction rate than using a combination of cellobiohydrolase - $\beta$-glucosidase or using $\beta$-glucosidase only.

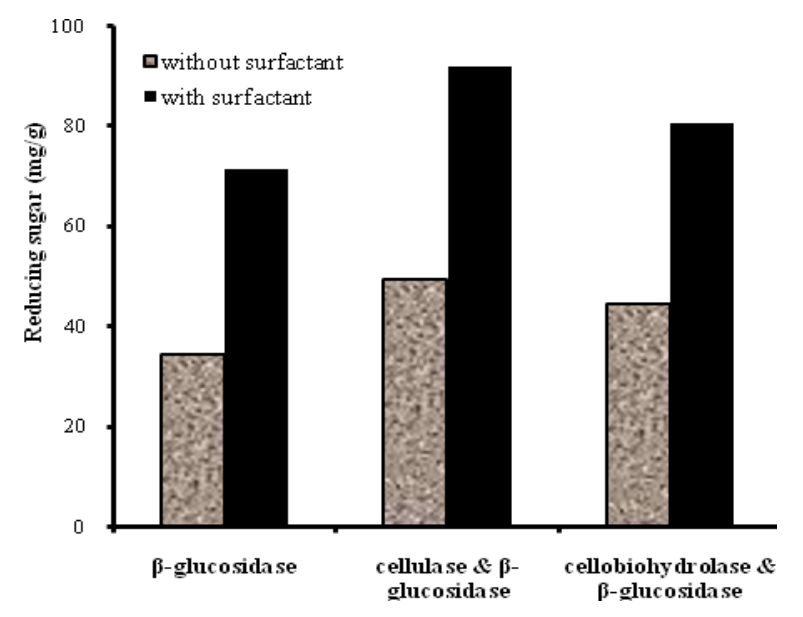

Fig.1. The effect of enzyme type and surfactant addition on the reducing sugar formation. The reaction time and surfactant concentration were $24 \mathrm{~h}$ and $1 \%(\mathrm{w} / \mathrm{w})$, respectively.

$\beta$-glucosidases primarily hydrolyze glycosidic bonds of the short chains polysaccharide. Disaccharide has been shown to have a stronger inhibitory effect on the enzymes than monosaccharide, and cellobiohydrolase produces disaccharides as the main product [12]. Mechanism of hydrolysis of chitosan by a combination of cellulase - $\beta$-glucosidase can be illustrated as: cellulase hydrolyzes chitosan to chitooligosaccharides chains, and $\beta$-glucosidase hydrolyzes oligomers to glucosamine monomers.

Fig. 1 also shows that Tween 80 could increase the formation of reducing sugars approximately two times higher than without Tween 80. Enzymatic hydrolysis was affected by the rates of adsorption and desorption of enzyme to the substrate [14]. The surfactant can improve a desorption of enzyme from a functional group of the substrate and then absorb another substrate functional group. The presence of acetyl groups in chitosan chain caused chitosan has hydrophobic properties [15]. The 
hydrophobicity of the backbone of chitosan chain played an important role in its interactions with surfactants [16].

\subsection{Effect of reaction time}

Fig. 2 shows the effect of reaction time on the formation of reducing sugar.

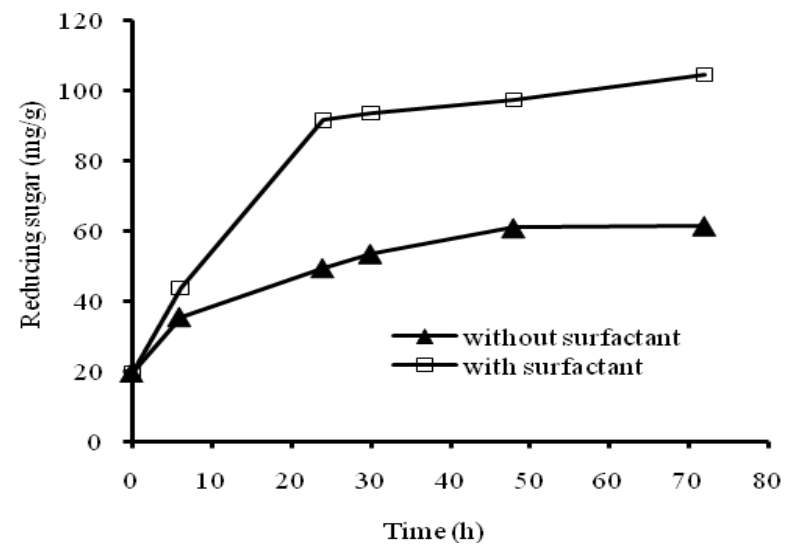

Fig. 2. The Effect of reaction times on the formation of reducing sugar. The enzyme type was a combination of cellulase $-\beta$-glucosidase.

During the entire time reaction, hydrolysis of chitosan with Tween 80 addition always possessed higher reducing sugar content than without Tween 80 addition. There was a sharp increase in the formation of reducing sugar within $24 \mathrm{~h}$. After 24 hours, the formation rate of reducing sugar decreased. This phenomenon is probably due to the inhibition of the enzyme activity by the end products. This statement is similar to the previous publications by Li et al. [17] and Zhou et al. [18].

\subsection{Characterization of the glucosamine}

The FT-IR spectra of raw and hydrolyzed chitosan (the enzyme type and reaction time were a combination of cellulase - $\beta$-glucosidase and $24 \mathrm{~h}$, respectively) are shown in Fig. 3.

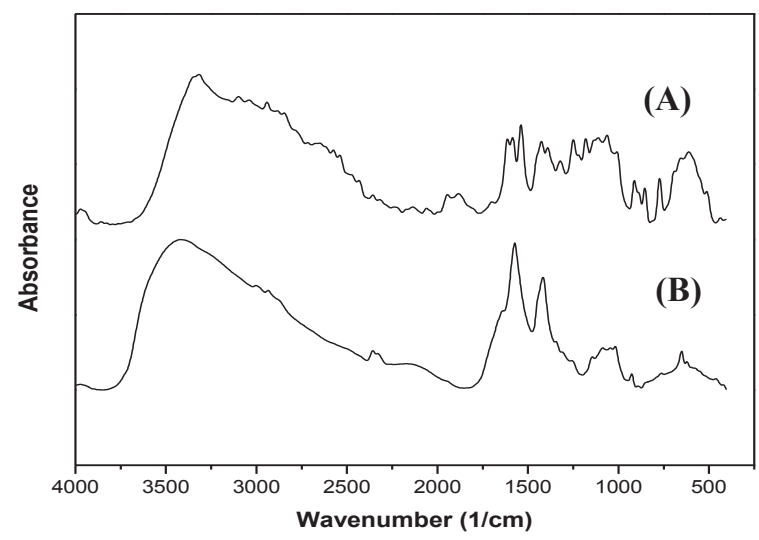

Fig. 3. FTIR spectra of raw chitosan (A) and hydrolyzed chitosan (B)
The spectrum of raw chitosan showed the absorption peaks at $3446.79,1595.13$, and $1423.47 \mathrm{~cm}^{-1}$, which indicates the amino peak characteristic of chitosan. The absorption peak at $1153 \mathrm{~cm}^{-1}$ indicates -C-O-Cglycosidic linkage between repeating unit of chitosan. These results are in good agreement with previous publications [19, 20]. The absorption peaks of glycosidic linkage disappear at spectra of hydrolyzed chitosan.
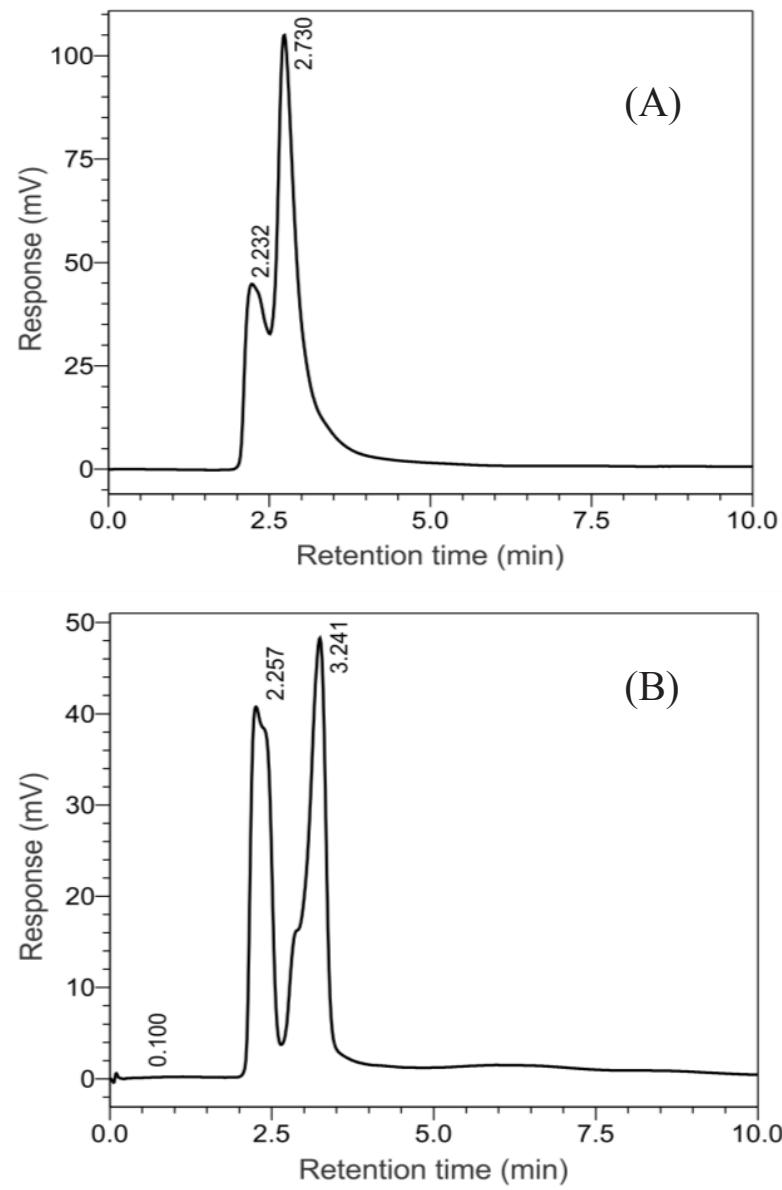

Fig.4. HPLC patterns : (A). Glucosamine hydrochloride and (B). Product of hydrolyzed chitosan

The molecular weight distribution of chitosan has been considered to be one of the most important characteristics affecting the functionality of the polymer [21]. The molecular weight distribution of the hydrolyzed chitosan product was analyzed using HPLC (Fig. 4). The eluted peak of the product of hydrolyzed chitosan similar with glucosamine hydrochloride (the retention time range about $2.4-2.7 \mathrm{~min}$ ). It shows that D-glucosamine can be produced by the enzymatic hydrolysis of chitosan using a combination of cellulase $\beta$-glucosidase.

\section{Conclusion}

Enzymatic hydrolysis of chitosan using various type enzyme with surfactant addition was investigated. The 
results of this study showed that addition of non-ionic surfactants Tween 80 could effectively increase enzymatic hydrolysis. Within the range studied, glucosamine could be prepared using a combination of cellulase $-\beta$-glucosidase with enzyme:chitosan ratio of $1: 100(\mathrm{w} / \mathrm{w})$ and the addition of surfactant Tween 80 $(1 \%, \mathrm{w} / \mathrm{w})$, at temperature $50{ }^{\circ} \mathrm{C}$ for 24 hours.

\section{References}

1. Y. Sun, J. Zhang, S. Wu, S. Wang, Int J Biol Macromol. 61 (2013).

2. R. Dalirfardouei, G. Karimi, K. Jamialahmadi, Life Sci. 152 (2016).

3. S.I. Sal'nikova, S.M. Drogovoz, I.A. Zupanets, Farmakol Toksikol. 53,4 (1990).

4. H.J. Oh, J.S. Lee, D.K. Song, D.H. Shin, B.C. Jang, S.I. Suh, J.W. Park, M.H. Suh, W.K. Baek, Biochem Bioph Res. Co. 360, 4 (2007).

5. K.A. Martin Xavier, K.G. Ramachandran, Standardization of Optimum Conditions for the Production of Glucosamine Hydrochiloride from Chitin, (Central Institute of Fisheries Technology, 2006)

6. I. Nagaoka, M. Igarashi, J. Hua, Y. Ju, S. Yomogida, K. Sakamoto, Carbohyd. Polym. 84, 2 (2011)

7. S. Sinha, R.. Kumar, S.R. Dhakate, S. Chand, IPCBEE. 9 (2011).

8. W. Xia, P. Liu, J. Zhang, J. Chen, Food Hydrocolloid, 25, 2 (2011)

9. N. Rokhati, H.Susanto, M. Waskito, R. Rahmawati, B. Pramudono, Adv Sci Lett. 23, 6 (2017)

10. Z. Zhang, C. Li, Q. Wang, Z.K. Zhao, Carbohyd. Polym. 78, 4 (2009).

11. L.R. Lynd, P.J. Weimer, W.H. Van Zyl, I.S. Pretorius, Microbiol. Mol. Biol. R. 66, 3 (2002).

12. N. Andersen, Enzymatic hydrolysis of cellulose. (Bio Centrum, Technical University of Denmark, 2007).

13. S.J. Horn, V.G. Eijsink, Carbohyd. Polym. 56, 1 (2004).

14. Y. Chen, X. Zhang, S. Zhang, W. Qin, C. Guo, X. Guo, D. Xiao, Turk. J. Biol. 38, 4 (2014)

15. C. Bangyekan, D. Aht-Ong, K.Srikulkit, Carbohyd. Polym. 63, 1 (2006)

16. I. Pepić, J. Filipović-Grčić, I. Jalšenjak, Colloid Surface A, 336,1 (2009).

17. J. Li, Y. Du, H. Liang, Polym Degrad Stabil. 92, 3 (2007).

18. Y. Zhou, H. Chen, F. Qi, X. Zhao, D. Liu, Bioresource Technol. 182 (2015)

19. H.Y. Zhou, X.G. Chen, M. Kong, C.S. Liu, D.S. Cha, J.F. Kennedy, Carbohyd. Polym. 73, 2 (2008)

20. I. Prasertsung, S. Damrongsakkul, N.Saito, Polym Degrad Stabil. 98, 10 (2013)

21. S.B. Lin, Y.C. Lin, H.H. Chen, Food Chem. 116, 1 (2009) 